Edith Cowan University

Research Online

Research outputs 2014 to 2021

2018

\title{
The potential synergistic behaviour of inter- and intra-genus probiotic combinations in the pattern and rate of short chain fatty acids formation during fibre fermentation
}

\author{
Warnakulasuriya M. A. D. B. Fernando \\ Edith Cowan University \\ Steve H. Flint \\ K. K. D. S. Ranaweera \\ Arthur Bamunuarachchi \\ Stuart K. Johnson
}

See next page for additional authors

Follow this and additional works at: https://ro.ecu.edu.au/ecuworkspost2013

Part of the Medical Neurobiology Commons

10.1080/09637486.2017.1340932

This is an Accepted Manuscript of an article published by Taylor \& Francis in the International Journal of Food Sciences and Nutrition on 28/6/2017, Available online: http://www.tandfonline.com/10.1080/ 09637486.2017 .1340932

This is an Author's Accepted Manuscript of:

Fernando, W. M., Flint, S. H., Ranaweera, K. K. D. S., Bamunuarachchi, A., Johnson, S. K., \& Brennan, C. S. (2018). The potential synergistic behaviour of inter-and intra-genus probiotic combinations in the pattern and rate of short chain fatty acids formation during fibre fermentation. International journal of food sciences and nutrition, 69(2), 144-154. doi:10.1080/09637486.2017.1340932

This Journal Article is posted at Research Online.

https://ro.ecu.edu.au/ecuworkspost2013/3899 


\section{Authors}

Warnakulasuriya M. A. D. B. Fernando, Steve H. Flint, K. K. D. S. Ranaweera, Arthur Bamunuarachchi, Stuart K. Johnson, and Charles S. Brennan 
The potential synergistic behaviour of inter- and intra genus probiotic combinations in the pattern and rate of short chain fatty acids formation during fibre fermentation.

Warnakulasuriya M. A.D. B. Fernando ${ }^{\mathrm{a}}$, Steve H Flint ${ }^{\mathrm{b}}$, KKDS Ranaweera ${ }^{\mathrm{c}}$, Arthur Bamunuarachchi ${ }^{\mathrm{d}}$, Stuart K. Johnson ${ }^{\mathrm{e}}$ Charles S. Brennan*f

${ }^{a}$ Centre of Excellence in Alzheimer's Disease Research and Care, School of Medical Sciences, Edith Cowan University, 6027, Australia.0863045844,w.fernando@ecu.edu.au.

b Institute of Food Nutrition and Human Health at Massey University, New Zealand,

\section{S.H.Flint@massey.ac.nz.}

'Department of Food Science and Technology, Sri Jayewardenepura University Srilanka, kkdsran@yahoo.com. ${ }^{\mathrm{d}}$. Department of Food Science and Technology, Sri Jayewardenepura University Srilanka, arthur_bamunu@yahoo.com

eDepartment of Food Science and Technology, Curtin University, Perth, Australia, S.Johnson@curtin.edu.au.

${ }^{\mathrm{f}}$ Department of Wine, Food and Molecular Biosciences, Centre for Food Research and Innovation, Lincoln University, PO Box 85084, Lincoln 7647, Christchurch, New Zealand, Brennan, Charles <Charles.Brennan@lincoln.ac.nz>

Key words- SCFA, Lactobacillus, Bifidobacterium , Rice fibre 


\section{The potential synergistic behaviour of inter- and intra genus probiotic combinations in}

the pattern and rate of short chain fatty acids formation in response to fibre fermentation.

\section{Abstract}

This study compared the rate of short chain fatty acid (SCFA) production by different probiotic combinations of Lactobacillus and Bifidobacterium to determine any synergistic effects. Six different fibre fractions were fermented with nine combinations of Lactobacillus rhamnosus (LR), Lactobacillus acidophilus (LA), Bifidobacterium longum (BL) and Bifidobacterium breve (BB) for 0, 6, 24 and 48 hours. SCFAs were quantified by gas chromatography. Intergenus combinations of bacteria produced more SCFA, especially BB+ BL+ LR, compared to intra-genus that yielded the lowest SCFA production. Acetate was the most abundant, while propionate and butyrate were the most utilized. The SCFA formation was as acetate > propionate $>$ butyrate and the total dietary fibre produced most of the SCFA. Most combinations utilized $60 \%$ - $80 \%$ of the fibre; BB+ BL+ LR digested the fibre completely. The quantity, pattern, and the time of release of SCFA is depend on the genus, but the combination of pre and probiotics is of great importance for the outcome.

\section{Introduction}

The human gastrointestinal microbiota is a complex ecosystem dominated by obligate anaerobes with $10^{11}$ cells per gram of intestinal content (Artis 2008, Wells et al. 2010). Although organisms are mainly responsible for nutrient fermentation, absorption, synthesis, inhibition of pathogenic microorganisms and stimulation of the human immune system (Krajmalnik-Brown et al. 2012, Wells, Loonen and Karczewski 2010), diet has been speculated to be a factor in controlling the number and the composition of these microbes resulting in either a healthy or unhealthy ecosystem in the human gut (Krajmalnik-Brown, Ilhan, Kang and DiBaise 2012). Consumption of a large number of refined and processed food modify the 
microbial ecosystem, causing an increased number of disorders including inflammatory bowel disease and atopic disorders(Krajmalnik-Brown, Ilhan, Kang and DiBaise 2012).

There is a plethora of information that assert food with probiotic either with multi strain or single species may support the reinstatement of the healthy balance of the gut micro flora. Further, products with mixture of probiotics may have the possible advantage over those containing single strains in terms of delivering health benefits (Chapman et al. 2011, Haller et al. 2010, Lema et al. 2001, Verna and Lucak 2010). Many different microorganisms have been identified as a probiotic and most of these microorganisms are naturally present in the human gastro intestinal tract (GIT). The most commonly identified probiotics belong to the bacterial genera Lactobacillus and Bifidobacterium, based on their role in prevention and treatment of various gastrointestinal disorders (Chmielewska and Szajewska 2010, Fijan 2014, Ruiz et al. 2013, Turroni et al. 2009, Walker 2013). Bifidobacterium that present in human gut are autochthonous and Bifidobacterium longum is one of the predominant species in adults, whereas Bifidobacterium breve is the major species in infants (Matsuki et al. 1999, Underwood et al. 2015). There are 17 Lactobacillus species that are associated with the human GIT as probiotics and the majority are allochthonous. L. acidophilus, L. casei, L. paracasei, L. rhamnosus, L. delbrueckii, L. brevis, L. johnsonii, L. plantarum, and L. fermentum are regularly present in fermented foods, and they are also common inhabitants of the oral cavity (Walter 2008).

Dietary fibres, exhibit a diverse range of physico-chemical properties that are important for the growth of probiotic microorganisms and thus are considered as prebiotics (Slavin 2013). The major end products of the fermentation of dietary fibre are short chain fatty acids ( SCFA); acetate, propionate and butyrate (den Besten et al. 2013). They are small molecules which have an array of biological functions, such as a histone deacetylase (HDAC) inhibitor, an energy metabolite to produce ATP and a G protein-coupled receptor (GPCR) activator (den Besten, 
van Eunen, Groen, Venema, Reijngoud and Bakker 2013). The SCFA also an energy source to epithelial cells. However, the rate, extent, and the molar ratio of SCFA formed by colonic microorganisms, are dependent upon the nature of the dietary fibre such as its solubility, degree of polymerization, type of linkages, branching, and monomeric composition as well as the profile of the microorganisms in the colon and their metabolic interactions (den Besten, van Eunen, Groen, Venema, Reijngoud and Bakker 2013). The mostly studied prebiotics are galacto-oligosaccharides (GOS), inulin and fructo-oligosaccharides (FOS), and lactulose (Slavin 2013), but studies are lacking with fibres from more commonly consumed foods such as rice, tea and coconut. In addition, few work has been identified combinations of different commonly used probiotics and prebiotics from commonly consumed and their synergistically enhanced viability and health beneficial metabolic activities of the probiotic microorganisms (Slavin 2013).

Our previously reported works evaluated the synergistic effect of insoluble (IDF), soluble (SDF) and total dietary fibre (SDF) of rice with Lactobacillus rhamnosus (LR), Lactobacillus acidophilus (LA), Bifidobacterium longum (BL) and Bifidobacterium breve (BB)(Fernando et al. 2010, Fernando et al. 2011, Fernando et al. 2008). Our previous work recognised high survival rate of the microrganisms with IDF, SDF and TDF of rice as single strains and as co cultures. Our studies further confirmed higher formation of SCFA when single strains were used. Previous studies have found that probiotics may influence SCFA formation by producing SCFA's themselves or by stimulating or suppressing the activity of other SCFA producing bacteria in the colon (den Besten, van Eunen, Groen, Venema, Reijngoud and Bakker 2013). Since the human gut has a symbiotic environment, metabolic consequences due to microbiological interactions cannot be identified simply from the substrate preferences and product formation of pure cultures, which limits the usefulness of previous research on single 
microorganism fermentation of food substrates. Therefore, studies with combinations of microorganisms are more realistic to the in vivo environment.

The main objective of the present study was to study the effects of different combinations of Lactobacillus rhamnosus (LR), Lactobacillus acidophilus (LA), Bifidobacterium longum (BL) and Bifidobacterium breve (BB) on the rate and profile of SCFA development during their fermentation of rice fibre.

\section{Material and Methods}

\section{Rice varieties}

Rice varieties were selected based on their milling grade to understand whether the milling grade has an impact on the fermentation by co-cultures. Two rice varieties were chosen:LD356 (RR1, red in colour, brown rice, dehulled) and AT353 (RR2, red in colour, unpolished, most of the germ having been removed).

\section{Determination of soluble, insoluble and total dietary fibre}

Soluble (SDF), insoluble (IDF) and total dietary fibre (TDF) of two rice varieties were isolated according to the AOAC method 991.43(McCleary et al. 2012). The ratio of SDF, IDF and TDF is different in each rice variety as shown in our previous studies (Fernando, Flint, Zou, Brennan, Ranaweera and Bamunuarachchi 2011). Fibre fractions from rice variety RR1 were designated as IDF1, SDF1 and TDF1 and those from variety RR2 designated as IDF2, SDF2 and TDF2.

\section{Bacterial strains}

Bacterial strains Lactobacillus rhamnosus (ATCC 7469) (LR), Lactobacillus acidophilus (ATCC11975) (LA), Bifidobacterium breve (ATCC15700) (BB), and Bifidobacterium longum (ATCC15707) (BL), were obtained from the culture collection at the Institute of Environmental Science and Research Limited, New Zealand.

\section{Co-cultures}


Pure cultures of bacterial strains were combined in a $1: 1(\mathrm{v} / \mathrm{v})$ ratio to prepare nine combinations in equal proportions. The population of each micro-organism which was incubated for $24 \mathrm{~h}$, was $10^{7} \mathrm{CFU} / \mathrm{mL}$, (OD $2.4-2.5$, at $540 \mathrm{~nm}$ ) at the time of mixing. The combinations were $\mathrm{LA}+\mathrm{LR}, \mathrm{BB}+\mathrm{BL}, \mathrm{BB}+\mathrm{LA}, \mathrm{BB}+\mathrm{LR}, \mathrm{BL}+\mathrm{LA}, \mathrm{BL}+\mathrm{LR}, \mathrm{BB}+\mathrm{BL}+\mathrm{LA}$, $\mathrm{BB}+\mathrm{BL}+\mathrm{LR}$, and $\mathrm{BB}+\mathrm{BL}+\mathrm{LA}+\mathrm{LR}$,

\section{Preparation of cell suspensions}

Freeze dried cultures were rehydrated by inoculating Lactobacillus spp. in de Man, Rogosa, and Sharpe (MRS) medium and Bifidobacterium spp. in Reinforced Clostridial medium, under strict anaerobic conditions. Anaerobic conditions were created by using an anaerobic chamber with the gas pack (Oxoid Ltd., Hampshire, England) throughout the experiment. Lactobacillus spp. were incubated at $37^{\circ} \mathrm{C}$ for $24 \mathrm{~h}$ and Bifidobacterium spp. were incubated at $37^{\circ} \mathrm{C}$ for $72 \mathrm{~h}$ to obtain the complete growth curves of the organisms. For the fermentation trials, the bacteria were sub-cultured twice in $10 \mathrm{ml}$ of the appropriate medium containing $10 \mathrm{~g} / \mathrm{l}$ glucose as the carbon source. After the incubation, the bacterial cells were centrifuged, washed twice with physiological saline $(0.85 \% \mathrm{NaCl}$ solution), and resuspended in the basal medium Peptone Yeast extract Fildes (PYF solution) to remove excess carbon before the fermentation trials. The suspension was then diluted to 1:10 with the basal medium (Jaskari et al. 1998). 


\section{Preparation of growth medium}

The basal medium, PYF solution, (carbohydrate-free medium), consisted of $10 \mathrm{~g}$ Trypticase Peptone, 5 g yeast extract, 0.5 g L-cysteine hydrochloride, $40 \mathrm{~mL}$ digested horse blood, and 40 $\mathrm{mL}$ salts solution per $1 \mathrm{~L}$. The salts solution contained $0.2 \mathrm{~g} \mathrm{CaCl}_{2}, 0.2 \mathrm{~g} \mathrm{MgSO}_{4} \cdot 7 \mathrm{H}_{2} 0,1.0$ $\mathrm{g} \mathrm{KH}_{2} \mathrm{PO}_{4}, 1.0 \mathrm{~g} \mathrm{~K}_{2} \mathrm{HPO}_{4}$.

\section{In-vitro fermentation with co-cultures}

Fermentations were conducted in sterile $100 \mathrm{~mL}$ bottles. Each bottle contained culture medium, substrate, and pure cultures. Culture medium $(50 \mathrm{~mL})$ and $1 \%(\mathrm{v} / \mathrm{v})$ substrate (extracted TDF, SDF or IDF from each of the rice varieties) were added to each bottle and sealed for $24 \mathrm{~h}$ for complete hydration of the fibre. The bottles were maintained at $37^{\circ} \mathrm{C}$ for $2 \mathrm{~h}$ prior to inoculation and $10 \%$ of the bacterial suspension of co-cultures $\left(10^{7}\right.$ colony forming units $\left.[\mathrm{cfu}] / \mathrm{mL}\right)$ were added to the broth medium (pH 7.6). Fermentation was conducted under strict anaerobic conditions. Fermentation was done in duplicate and aliquots were removed at 0, 6, 12, 18, 24 , 36 and $48 \mathrm{~h}$ after incubation. A volume of $1 \mathrm{~mL}$ was used to prepare a 10 -fold dilution series to analyse viable count, a volume of $1.5 \mathrm{~mL}$ was taken to measure the optical density (540 nm) and 2-3 mL was taken for $\mathrm{pH}$ measurement. Aliquots of $2 \mathrm{~mL}$ were removed at $0,6,12,18$, 24,36 and $48 \mathrm{~h}$ after incubation for SCFA analysis, and the growth of microbes was stopped by adding $1 \mathrm{~mL}$ of $10 \mathrm{~g} / \mathrm{L}$ copper sulphate. Gas packs were replaced with new packs after each aliquot was removed. The samples were kept at $-20{ }^{\circ} \mathrm{C}$ for further processing. Fermentation was carried out in duplicates and two independent experiments were done.

\section{Determination of SCFA by gas chromatography}

\section{Chemicals and reagents to prepare standards}


Acetic acid (100\%) was obtained from Merck (Darmstadt, Germany). Propionic acid (100\%)), n-butyric acid (99\%), were purchased from Sigma (St Louis, MO, USA). These chemicals were used as standards for GLC. 2-Ethylbutyric acid purchased from Sigma-Aldrich (Chemie GmbH, Steinheim, Germany) was used as an internal standard. The water used in the experiment was purified using a Milli-Q ${ }^{\circledR}$ reagent water system (Millipore, Molsheim, France).

\section{Preparation of samples for Gas Chromatography}

Samples were thawed and the $\mathrm{pH}$ was adjusted to 6.5 with $4 \mathrm{M} \mathrm{KOH}$ followed by adding 0.01 $\mathrm{mL}$ of 0.3M oxalic acid(Pylkas, Juneja and Slavin 2005).

\section{Preparation of stock standard solution}

An aqueous stock standard solution was prepared for each acid with a concentration of 500 $\mathrm{mM}$ for acetic acid and 200mM for propionic acid and n-butyric acid. 2-Ethylbutyric acid solution (4 mM) in methanol was prepared as an internal standard stock solution. All the stock standard solutions were stored at $-20^{\circ} \mathrm{C}$.

\section{Preparation of standard mix solution}

A standard mix solution of acetic, propionic and butyric was prepared in water using stock solutions at 50:10: 10, 35:7.5:7.5, 20: 10:10, 25:5:5 and 15:2.5:2.5 mM.

\section{Experimental conditions for gas chromatography}

Analyses were performed using an Agilent 6890N GC (Hewlett Packard, Palo Alto, CA, USA) with a flame ionization detector (FID). A fused-silica capillary column with a free fatty acid phase (DB-FFAP 125-3237, J\&W Scientific, Agilent Technologies Inc., USA) of $30 \mathrm{~m} \times 0.53$ $\mathrm{mm}$ and with $0.50 \mu \mathrm{m}$ film thickness was used. Helium was the carrier gas at a flow rate of $14.4 \mathrm{~mL} / \mathrm{min}$. The initial oven temperature was $60{ }^{\circ} \mathrm{C}$, maintained for $0.5 \mathrm{~min}$, raised to 180 ${ }^{\circ} \mathrm{C}$ at $8{ }^{\circ} \mathrm{C} / \mathrm{min}$ and held for $1 \mathrm{~min}$, then increased to $250{ }^{\circ} \mathrm{C}$ at $20^{\circ} \mathrm{C} / \mathrm{min}$, and finally held at $250^{\circ} \mathrm{C}$ for 5 min. Glass wool (Supelco 20411; Sigma Aldrich) was placed in the glass liner of 
the split less injection port. These glass wool was prepared by immersing in $\mathrm{H}_{3} \mathrm{PO}_{4}(100 \mathrm{~g} / \mathrm{L})$ for $1 \mathrm{~h}$ and rinsing to remove the excess acid before placing in a $100{ }^{\circ} \mathrm{C}$ oven for $1 \mathrm{~h}$. The temperature of the flame ionization detector and the injection port was 240 and $200{ }^{\circ} \mathrm{C}$, respectively. Flow rates of nitrogen, hydrogen and air were 20, 30 and $275 \mathrm{~mL} / \mathrm{min}$, respectively. The injected sample volume was $1 \mu \mathrm{L}$, and the run time for each analysis was 16.5 min. Data handling was carried out with HP Chem Station Plus software (A.09.xx, Agilent). Unknown peaks did not interfere with SCFA peaks of interest and the appearance of ghost peaks was not significant. $1 \mu \mathrm{L}$ of water was injected before starting the analysis and after 10 runs to remove the unknown impurities of the column.

The SFCA's produced by fermentation, were determined by the method of Pylkas et al. 2005 with minor modifications. Samples $(2 \mathrm{~mL})$ that had been taken at the required fermentation time, (stored frozen) thawed and centrifuged for 30 minutes at $5000 \mathrm{x} \mathrm{g}$ at room temperature (In original method-3000 $\mathrm{x}$ g). The supernatant $(0.75 \mathrm{~mL})$ was transferred to a sterile vial and vortex mixed with meta-phosphoric acid (20\%, $0.3 \mathrm{~mL})$. Vials were incubated with metaphosphoric acid at room temperature for $30 \mathrm{~min}$, after which samples were centrifuged for 20 min at 20,000 g for $10 \mathrm{~min}$ (In original method-5000 x g for $15 \mathrm{~min}$ ). The supernatant was analysed for SCFA by GLC. Samples were stored at -20 o $\mathrm{C}$ for further processing. Centrifugation times are different from original method as described.

Standard curve, Retention time of standards, Quantification, Calculation of relative response factor (RRF), Concentration of SCFA $\mathrm{mM}$ in sample

All these methods are described in our previous papers (Fernando et al. 2008, 2010)

Determination of the indigestible percentage of soluble dietary fibre (following fermentation of SDF)

The supernatant (5 mL) (used for SCFA analysis) was centrifuged at $24000 *$ g for $15 \mathrm{~min}$ at room temperature to remove bacteria (Titgemeyer et al. 1991). The resulting supernatant was 
mixed with four volumes of $95 \%$ of ethanol to precipitate the soluble dietary fibre. The precipitate was isolated by filtration with 541 filter paper (Whatman Internationational Ltd, Maidstone, UK). The paper and residue was dried at $105{ }^{\circ} \mathrm{C}$ and weighed. After correction for residue from the blank tubes, this residue was considered the non-fermented soluble fibre. Blank tubes were prepared for each combination without adding the substrate to make the appropriate corrections for the inocula.

Determination of the indigestible percentage of insoluble dietary fibre (following fermentation of IDF)

The pellet from centrifugation of $5 \mathrm{~mL}$ supernatant from the initial centrifugation used for SCFA analysis was re suspended in one $\mathrm{mL}$ acid pepsin solution (Pepsin a, 1:10000, Sigma Chemical Co, Balcatta, WA) and incubated for $48 \mathrm{~h}$ at $37^{\circ} \mathrm{C}$. After incubation the suspension was filtered through 541 filter paper (Whatman Internationational Ltd Maidstone, UK). The paper and residue was dried at $105{ }^{\circ} \mathrm{C}$ and weighed. After correction for the residue from the blank tubes, this residue was considered as non-fermented insoluble fibre (Tilley and Terry 1963).

Determination of the indigestible percentage of total dietary fibre (following fermentation of TDF)

The indigestible quantity of SDF and IDF was measured using above methods from $5 \mathrm{~mL}$ of the aliquots of the fermentation broth at each time point. The sum of both SDF and IDF was considered as the indigestible amount of TDF.

Determination of the percentage of dry matter disappearance

$\{[($ Substrate dry matter - (residual dry matter (IDF/SDF/TDF)] - blank weight) / substrate dry matter]\}x100 
Percentage of dry matter disappearance was calculated by a modification of a previous formula (McBurney and Thompson 1987).

\section{Statistical analysis}

The in vitro fermentation experiment was conducted as a randomised complete block with 9 combinations of micro-organisms serving as blocks. Treatment was factorially arranged with three substrates (IDF, SDF and TDF) and six lengths of fermentation (0, 6,18, 24,36 and 48 h). The analyses were performed in duplicates and results were expressed as mean values and SD. Data were analysed using the statistical analysis package of Microsoft Excel 2003. Statistical evaluations between groups were performed using Analysis of variance, Paired Student $\mathrm{t}$ tests followed by Tukey-Kramer honest significance difference test to establish differences between group means, and by a Dunnet test to compare each group with controls.

\section{Results}

\section{Trend of SCFA formation}

All the combinations produced more acetate $(\mathrm{p}<0.05)$ than propionate and butyrate, results of three combinations are shown in the Table 1 . The amount of the acetate formed by intra-genus combinations was less than inter- genus combinations. There was no significant difference $(\mathrm{p}<0.5)$ in propionate and butyrate produced by different combinations. This indicates that when these microorganisms work as co-cultures, they produce more acetate from fibre fermentation than propionate and butyrate. The present study identified two clearly distinct types of SCFA formation from combinations. Intra-genus combinations formed less SCFA than those containing members of a different genus (Figures 1 and 2). For instance, the combinations of $\mathrm{BB}+\mathrm{BL}$ and $\mathrm{LA}+\mathrm{LR}$ produced significantly $(\mathrm{p}<0.05)$ less SCFA than those containing more than one genus. Similar results were observed with ropy strains of yoghurt culture, where combinations of ropy cultures, did not improve the final texture more than the combinations of ropy and non-ropy strains(Rawson and Marshall 1997). Species belonging to the same genus 
are likely to have similar nutrient requirements and may result in competition for adherence to fibre, fibre hydrolysis, and utilization of hydrolytic products, all leading to a reduction of the potential amount of metabolite formation. Microorganisms belonging to a different genus are more likely than those of the same genus to interact synergistically (Cheirsilp et al. 2003, Corsetti et al. 2004, Loessner et al. 2003) with the metabolite formation of mixed cultures appearing to be strain specific as reported previously (Saulnier et al. 2007).

\section{The rate of SCFA formation}

The rate of SCFA formation also varied among the combinations and was dependent on the time point. The combinations $\mathrm{LA}+\mathrm{LR}$ and $\mathrm{BB}+\mathrm{BL}$ had the lowest rate of SCFA formation, while combinations with members of a different genus had higher rate of SCFA formation. The later combination produced more SCFA after $24 \mathrm{~h} \mathrm{~s}$ of fermentation and this was compatible with their growth curve (Fernando, Flint, Zou, Brennan, Ranaweera and Bamunuarachchi 2011) which we studied previously. Among all the combinations $\mathrm{BB}+\mathrm{BL}+\mathrm{LR}$ produced a significantly higher $(\mathrm{P}<0.05)$ amount of total SCFA at $6 \mathrm{~h}$ and $24 \mathrm{~h}$ (Figure 1 and 2), suggesting their effectiveness as co-cultures in terms of SCFA formation. 


\section{The quantity of SCFA formation}

The quantity of SCFA formation was as acetate $>$ propionate $\geq$ butyrate for all the combinations. Acetate formation increased in the first 24 hours of fermentation, but propionate and butyrate had a lower progression throughout the fermentation. The low level of propionate and butyrate indicates that microorganisms might have utilized propionate and butyrate as an energy source for their survival. Another explanation for the lower propionate and butyrate formation by the microorganisms throughout the present study might be attributed to the nature of the strains used, as well as to the different composition of sugars in the dietary fibre fractions.

\section{Digestion of fibre by Bifidobacterium and Lactobacillus}

Intra-genus combinations digested rice fibre less than the other combinations (Table 2), with the amount of undigested fibre appearing to be strain specific. Among the mix combinations, combinations that contained Bifidobacterium showed a reduced level of substrates after $48 \mathrm{~h}$. Combinations such as $\mathrm{BB}+\mathrm{BL}+\mathrm{LA}$ and $\mathrm{BB}+\mathrm{BL}+\mathrm{LR}$ had less than $5 \%$ remaining after $48 \mathrm{~h}$ for SDF of RR2. Total dietary fibre and SDF of RR2 was most preferable type of fibre by all the combinations. It is also worth noting that $50 \%$ of fibre were utilised within $24 \mathrm{hs}$, irrespective of type of fibre and combination.

\section{SCFA formation based on the type of fibre}

The amount of metabolites formed varied with the different substrates. All the co-cultures formed a greater amount of SCFA with TDF than with the IDF and SDF (Figure 2). This indicates that the most preferred fibre fraction was TDF for selected microbial combinations. SCFA formation among the fibre fractions followed the pattern TDF $>$ SDF $>$ IDF. Interestingly, the formation of SCFA with glucose was not higher than the TDF. Glucose is a mono saccharide whereas rice fibre fractions are likely to contain mixed glucan components. This observation indicates that the complex nature of dietary fibre does not limit fermentation rate of glucan units. 


\section{Discussion}

Short-chain fatty acids (SCFAs) are recognised as an important microbial end-product of the fermentation in the human colon (Louis et al. 2014). The quantity and ratio of SCFA (as acetate, propionate, butyrate) in the human gut is considered as a biomarker for a healthy human gut (Brussow and Parkinson 2014, David et al. 2014).

Previous work has illustrated that acetate is the most abundant SCFA in the colon and this agreed with our observations, yielding acetate more than $50 \%$ of total SCFA production (Fernando, Ranaweera, Bamunuarachchi and Brennan 2008, Louis et al. 2007) irrespective of combination differences (Table 1). However, higher quantity of acetate was observed from the combinations enriched with Bifidobacterium than the combinations of Lactobacillus (Table 1). Although, literature indicates most enteric bacteria as well as acetogenic bacteria produce acetate (Fernando, Ranaweera, Bamunuarachchi and Brennan 2008) as a result of fermentation of carbohydrate or using Wood-Ljungdahl pathway (Louis, Hold and Flint 2014) in human gut, Bifidobacterium metabolise carbohydrate through a particular metabolic pathway, named the "bifid shunt", where the fructose-6-phosphoketolase enzyme is involved (de Vries and Stouthamer 1967). This pathway yields more energy in the form of ATP from carbohydrates for Bifidobacterium than the fermentative pathways for Lactobacillus which converts acetyl phosphate in to acetate without using ATP. Bifidobacterium generate 2.5 ATP molecules from $1 \mathrm{~mol}$ of fermented glucose, as well as $1.5 \mathrm{~mol}$ of acetate and $1 \mathrm{~mol}$ of lactate (Palframan et al. 2003) whereas the heterofermentative Lactobacillus produce 1 mol of ATP (Tamime 2013), 0.5 moles of lactate, and 0.5 moles of ethanol or acetate using transketolase pathway (Pessione 2012). This may explain higher quantity of acetate generated from the combinations enriched with Bifidobacterium than the combinations of Lactobacillus (Table 1).

Previous research on the fermentation of dietary fibre demonstrated increased ratio of butyrate formation (Berggren et al. 1993, Khan and Edwards 2005) by organisms in the rat caecum 
which had mixture of probiotic combinations(Nilsson et al. 2006). In contrast, our current work, the ratio of propionate and butyrate was significantly less $(\mathrm{p}<0.05)$ than acetate for all the combinations and for all the fractions of fibre (Table 1). Our results also indicated the microorganisms in the combinations of $\mathrm{BB}+\mathrm{BL}+\mathrm{LR}$ produced the lowest ratio for acetate to propionate, as acetate formation was high in these combinations. However, literature states that acetate can be converted into butyrate through cross-feeding interactions(De Vuyst and Leroy 2011, De Vuyst et al. 2014). Therefore, excess acetate may be converted in to butyrate. In summary, having a synergistic combinations of prebiotic and probiotic which can produce higher quantity of acetate is beneficial to enhance formation of butyrate in human gut. Research has suggested that a low ratio between acetate to propionate is important to reduce the human serum cholesterol level in men and also reported diseases such as, ulcerative colitis (Machiels et al. 2014) and asthma cause (Arrieta et al. 2015) to have low number of butyrate and propionate producers such as Faecalibacterium Lachnospira, Veillonella, and Rothia (FLVR)— in human.

This study found a unique array of SCFA formation from fibre by combinations of more than two microorganisms. The total amount of SCFA produced by combinations of more than two microorganisms varied with $\mathrm{BB}+\mathrm{BL}+\mathrm{LR}>\mathrm{BB}+\mathrm{BL}+\mathrm{LA}>\mathrm{BB}+\mathrm{BL}+\mathrm{LA}+\mathrm{LR}$. These three combinations produced more SCFA than the other combinations and much more than the $\mathrm{BB}+\mathrm{BL} / \mathrm{LA}+\mathrm{LR}$ combinations. This suggests metabolism of fibre fractions could be changed due to the changes of the organisms. Similar observations have been recorded with gut organisms of the rat with the addition of Bifidobacterium with inulin and pectin (Nilsson, Nyman, Ahrné, Sullivan and Fitzgerald 2006). The results also suggested that BB+BL have the ability to work synergistically with the growth of Lactobacillus species. This type of positive interactions are always an important in the succession of microbes in fermentation ecosystems. 
This may be due to the metabolic cross-feeding or substrate cross feeding (Belenguer et al. 2006).

Bifidobacterium genomes possess high numbers of genes encoding glycoside hydrolases which play a role in the degradation of carbohydrates (van den Broek et al. 2008). Therefore, Bifidobacterium are particularly in efficient uptake of oligosaccharides and to degrade them into monosaccharides (Van der Meulen et al. 2004). Researchers have also identified that Bifidobacterium utilise non-digestible carbohydrates as energy sources, including resistant starch, pectin, inulin, arabinoxylan (AX), cellulose, and their corresponding oligosaccharides, but this ability is strain-dependent (McLaughlin et al. 2015, Selak et al. 2016). Genomes of Lactobacillus encodes numerous genes involved in the metabolism of a variety of carbohydrates specially tri- and tetrasaccharides (Makarova et al. 2006). However, most of the enzymes that are responsible for the digestion are intracellular complexes such as glycosyl hydrolases that clearly differentiates Lactobacillus from Bifidobacterium (Sela et al. 2008). This was further evidenced with the observed digestion pattern of the current work (Table 2). The combinations rich with Bifidobacterium had a higher rate of digestion of fibre than the other combinations. For instance, the combination of $\mathrm{BB}+\mathrm{BL}+\mathrm{LR}$ digested the SDF of both rice varieties and TDF of RR2 completely.

\section{Conclusion}

The results from the fermentation of fibre by combinations of microorganisms are assumed to relate to the microbial activity that is likely to occur in the human gut. The findings of the present study indicate that supplementing the diet with fibre especially rice fibre will stimulate the formation of acetate in human gut which could in turn results in formation of higher quantity of butyrate. All the microbial combinations produced the SCFA under low oxygen and highly reducing experimental conditions, similar to conditions in the distal colon. 
The site of fermentation in human gut may also influence the quantity of SCFA. The current study also illustrated a degree of synergistic behavior in inter-genus probiotic fermentations indicating the potential use of multi genus combinations in the creation of probiotic resources for the food industry. The findings of this study advances the knowledge on the efficacy of combinations of probiotic bacteria for the development of synbiotic products.

Acknowledgement,

The authors gratefully acknowledge the support from the Asian Development Bank .All authors contributed to the literature search, analysis of the data published, manuscript writing and revisions of the article. The authors declare no conflicts of interest arising from the conclusions of this research.

References

Arrieta MC, Stiemsma LT, Dimitriu PA, Thorson L, Russell S, Yurist-Doutsch S, Kuzeljevic B, Gold MJ, Britton HM, Lefebvre DL, et al. 2015. Early infancy microbial and metabolic alterations affect risk of childhood asthma. Sci Transl Med.7:307ra152.

Artis D. 2008. Epithelial-cell recognition of commensal bacteria and maintenance of immune homeostasis in the gut. Nat Rev Immunol.8:411-420.

Belenguer A, Duncan SH, Calder AG, Holtrop G, Louis P, Lobley GE, Flint HJ. 2006. Two routes of metabolic cross-feeding between Bifidobacterium adolescentis and butyrate-producing anaerobes from the human gut. Appl Environ Microbiol.72:3593-3599.

Berggren AM, Björck IME, Nyman EMGL, Eggum BO. 1993. Short-chain fatty acid content and pH in caecum of rats given various sources of carbohydrates. J Sci Food Agr.63:397-406.

Brussow H, Parkinson SJ. 2014. You are what you eat. Nat Biotechnol.32:243-245.

Chapman CMC, Gibson GR, Rowland I. 2011. Health benefits of probiotics: are mixtures more effective than single strains? Eur J Clin Nutr 50:1-17.

Cheirsilp B, Shoji H, Shimizu H, Shioya S. 2003. Interactions between Lactobacillus kefiranofaciens and Saccharomyces cerevisiae in mixed culture for kefiran production. J Biosci Bioeng.96:279-284.

Chmielewska A, Szajewska H. 2010. Systematic review of randomised controlled trials: probiotics for functional constipation. World J Gastroenterol.16:69-75.

Corsetti A, Settanni L, Van Sinderen D. 2004. Characterization of bacteriocin-like inhibitory substances (BLIS) from sourdough lactic acid bacteria and evaluation of their in vitro and in situ activity. J Appl Microbiol.96:521-534.

David LA, Maurice CF, Carmody RN, Gootenberg DB, Button JE, Wolfe BE, Ling AV, Devlin AS, Varma Y, Fischbach MA, et al. 2014. Diet rapidly and reproducibly alters the human gut microbiome. Nature.505:559-563. 
de Vries W, Stouthamer AH. 1967. Pathway of glucose fermentation in relation to the taxonomy of bifidobacteria. J Bacteriol.93:574-576.

De Vuyst L, Leroy F. 2011. Cross-feeding between bifidobacteria and butyrate-producing colon bacteria explains bifdobacterial competitiveness, butyrate production, and gas production. Int J Food Microbiol.149:73-80.

De Vuyst L, Moens F, Selak M, Riviere A, Leroy F. 2014. Summer Meeting 2013: growth and physiology of bifidobacteria. J Appl Microbiol.116:477-491.

den Besten G, van Eunen K, Groen AK, Venema K, Reijngoud D-J, Bakker BM. 2013. The role of shortchain fatty acids in the interplay between diet, gut microbiota, and host energy metabolism. J Lipid Res.54:2325-2340.

Fernando WMADB, Brennan CS, Flint S, Ranaweera KKDS, Bamunuarachchi A, Morton HR. 2010. Enhancement of short chain fatty acid formation by pure cultures of probiotics on rice fibre. IJFST.45:690-696.

Fernando WMADB, Flint S, Zou M, Brennan CS, Ranaweera KKDS, Bamunuarachchi A. 2011. The effect of rice fibre fractions on the growth of co-cultures of probiotics. JFST.48:14-25.

Fernando WMADB, Ranaweera KKDS, Bamunuarachchi A, Brennan CS. 2008. The influence of rice fibre fractions on the in vitro fermentation production of short chain fatty acids using human faecal micro flora. IJFST.43:2237-2244.

Fijan S. 2014. Microorganisms with Claimed Probiotic Properties: An Overview of Recent Literature. Int J Environ Res Publ Health.11:4745-4767.

Haller D, Antoine J-M, Bengmark S, Enck P, Rijkers GT, Lenoir-Wijnkoop I. 2010. Guidance for Substantiating the Evidence for Beneficial Effects of Probiotics: Probiotics in Chronic Inflammatory Bowel Disease and the Functional Disorder Irritable Bowel Syndrome. J Nutr.140.

Jaskari J, Kontula P, Siitonen A, Jousimies-Somer H, Mattila-Sandholm T, Poutanen K. 1998. Oat betaglucan and xylan hydrolysates as selective substrates for Bifidobacterium and Lactobacillus strains. Appl Microbiol Biotechnol.49:175-181.

Khan KM, Edwards CA. 2005. In vitro fermentation characteristicsof a mixture of Raftilose and guar gumby human faecal bacteria. Eur J Clin Nutr.44:371-376.

Krajmalnik-Brown R, Ilhan Z-E, Kang D-W, DiBaise JK. 2012. Effects of Gut Microbes on Nutrient Absorption and Energy Regulation. Nutr Clin Pract.27:201-214.

Lema M, Williams L, Rao DR. 2001. Reduction of fecal shedding of enterohemorrhagic Escherichia coli O157:H7 in lambs by feeding microbial feed supplement. Small Ruminant Research.39:31-39.

Loessner M, Guenther S, Steffan S, Scherer S. 2003. A pediocin-producing Lactobacillus plantarum strain inhibits Listeria monocytogenes in a multispecies cheese surface microbial ripening consortium. Appl Environ Microbiol.69:1854-1857.

Louis P, Hold GL, Flint HJ. 2014. The gut microbiota, bacterial metabolites and colorectal cancer. Nat Rev Microbiol.12:661-672.

Louis P, Scott KP, Duncan SH, Flint HJ. 2007. Understanding the effects of diet on bacterial metabolism in the large intestine. J Appl Microbiol.102:1197-1208.

Machiels K, Joossens M, Sabino J, De Preter V, Arijs I, Eeckhaut V, Ballet V, Claes K, Van Immerseel F, Verbeke K, et al. 2014. A decrease of the butyrate-producing species Roseburia hominis and Faecalibacterium prausnitzii defines dysbiosis in patients with ulcerative colitis. Gut.63:1275-1283.

Makarova K, Slesarev A, Wolf Y, Sorokin A, Mirkin B, Koonin E, Pavlov A, Pavlova N, Karamychev V, Polouchine $\mathrm{N}$, et al. 2006. Comparative genomics of the lactic acid bacteria. Proc Natl Acad Sci 103:15611-15616.

Matsuki T, Watanabe K, Tanaka R, Fukuda M, Oyaizu H. 1999. Distribution of Bifidobacterial Species in Human Intestinal Microflora Examined with 16S rRNA-Gene-Targeted Species-Specific Primers. Appl Environ Microbiol 65:4506-4512.

McBurney MI, Thompson LU. 1987. Effect of human faecal inoculum on in vitro fermentation variables. BJN.58:233-243. 
McCleary BV, DeVries JW, Rader JI, Cohen G, Prosky L, Mugford DC, Okuma K. 2012. Determination of insoluble, soluble, and total dietary fiber (CODEX definition) by enzymatic-gravimetric method and liquid chromatography: collaborative study. J AOAC Int.95:824-844.

McLaughlin HP, Motherway MO, Lakshminarayanan B, Stanton C, Paul Ross R, Brulc J, Menon R, O'Toole PW, van Sinderen D. 2015. Carbohydrate catabolic diversity of bifidobacteria and lactobacilli of human origin. Int J Food Microbiol.203:109-121.

Nilsson U, Nyman M, Ahrné S, Sullivan EO, Fitzgerald G. 2006. Bifidobacterium lactis Bb-12 and Lactobacillus salivarius UCC500 Modify Carboxylic Acid Formation in the Hindgut of Rats Given Pectin, Inulin, and Lactitol. J Nutr.136:2175-2180.

Palframan RJ, Gibson GR, Rastall RA. 2003. Carbohydrate preferences of Bifidobacterium species isolated from the human gut. Curr Issues Intest Microbiol.4:71-75.

Pessione E. 2012. Lactic acid bacteria contribution to gut microbiota complexity: lights and shadows. Front Cell Infect Microbiol.2:86.

Rawson HL, Marshall VM. 1997. Effect of 'ropy' strains of Lactobacillus delbrueckii ssp. bulgaricus and Streptococcus thermophilus on rheology of stirred yogurt. IJFST.32:213-220.

Ruiz L, Margolles A, Sanchez B. 2013. Bile resistance mechanisms in Lactobacillus and Bifidobacterium. Front Microbiol.4:396.

Saulnier DM, Molenaar D, de Vos WM, Gibson GR, Kolida S. 2007. Identification of prebiotic fructooligosaccharide metabolism in Lactobacillus plantarum WCFS1 through microarrays. Appl Environ Microbiol.73:1753-1765.

Sela DA, Chapman J, Adeuya A, Kim JH, Chen F, Whitehead TR, Lapidus A, Rokhsar DS, Lebrilla CB, German JB, et al. 2008. The genome sequence of Bifidobacterium longum subsp. infantis reveals adaptations for milk utilization within the infant microbiome. Proc Natl Acad Sci U S A.105:1896418969.

Selak M, Riviere A, Moens F, Van den Abbeele P, Geirnaert A, Rogelj I, Leroy F, De Vuyst L. 2016. Inulintype fructan fermentation by bifidobacteria depends on the strain rather than the species and region in the human intestine. Appl Microbiol Biotechnol.100:4097-4107.

Slavin J. 2013. Fiber and Prebiotics: Mechanisms and Health Benefits. Nutrients.5:1417-1435.

Tamime AY. 2013. Lactic Acid Bacteria - Microbiological and Functional Aspects (2012). Int J Dairy Technol.66:149-150.

Tilley JMA, Terry RA. 1963. A Two-Stage Technique For The In Vitro Digestion Of Forage Crops. Grass Forage Sci.18:104-111.

Titgemeyer EC, Cameron MG, Bourquin LD, Fahey GC. 1991. Digestion of Cell Wall Components by Dairy Heifers Fed Diets Based on Alfalfa and Chemically Treated Oat Hulls. J Dairy Sci.74:1026-1037. Turroni F, Foroni E, Pizzetti P, Giubellini V, Ribbera A, Merusi P, Cagnasso P, Bizzarri B, de'Angelis GL, Shanahan F, et al. 2009. Exploring the Diversity of the Bifidobacterial Population in the Human Intestinal Tract. Appl Environ Microbiol 75:1534-1545.

Underwood MA, German JB, Lebrilla CB, Mills DA. 2015. Bifidobacterium longum subspecies infantis: champion colonizer of the infant gut. Pediatr Res.77:229-235.

van den Broek LA, Hinz SW, Beldman G, Vincken JP, Voragen AG. 2008. Bifidobacterium carbohydrases-their role in breakdown and synthesis of (potential) prebiotics. Mol Nutr Food Res.52:146-163.

Van der Meulen R, Avonts L, De Vuyst L. 2004. Short fractions of oligofructose are preferentially metabolized by Bifidobacterium animalis DN-173 010. Appl Environ Microbiol.70:1923-1930.

Verna EC, Lucak S. 2010. Use of probiotics in gastrointestinal disorders: what to recommend? Therap Adv Gastroenterol.3:307-319.

Walker WA. 2013. Initial intestinal colonization in the human infant and immune homeostasis. Ann Nutr Metab.63 Suppl 2:8-15.

Walter J. 2008. Ecological Role of Lactobacilli in the Gastrointestinal Tract: Implications for Fundamental and Biomedical Research. Appl Environ Microbiol 74:4985-4996. 
Wells JM, Loonen LM, Karczewski JM. 2010. The role of innate signaling in the homeostasis of 